\title{
mPW1PW91 Calculated Structures and IR Spectra of Thiacalix[4]biscrown-5 Complexed with Alkali Metal Ions
}

\author{
Jong-In Choe* \\ Department of Chemistry, Chung-Ang University, Seoul 156-756, Korea. E-mail: choeji@cau.ac.kr \\ Received January 10, 2011, Accepted February 21, 2011
}

\begin{abstract}
The molecular structures of thiacalix[4]biscrown-5 (1) and p-tert-butylthiacalix[4]biscrown-5 (2) and their alkali-metal-ion complexes were optimized using the DFT BLYP/6-31G(d) and $m$ PW1PW91/6-31G(d,p) (hybrid HF-DF) calculations. The total electronic energies, the normal vibrational modes, and the Gibbs free energies of the mono- and di-topic complexes of each host with the sodium and potassium ions were analyzed. The $\mathrm{K}^{+}$-complexes exhibited relatively stronger binding efficiencies than $\mathrm{Na}^{+}$-complexes for both the monoand di-topic complexes of $\mathbf{1}$ and $\mathbf{2}$ comparing the efficiencies of the sodium and potassium complexes with an anisole and phenol. The mPW1PW91/6-31G(d,p) calculated distances between the oxygen atoms and the alkali metal ions were reported in the alkali-metal-ion complexes $\left(\mathbf{1} \cdot \mathrm{Na}^{+}, \mathbf{1} \cdot 2 \mathrm{Na}^{+}, \mathbf{1} \cdot \mathrm{K}^{+}, \mathbf{1} \cdot 2 \mathrm{~K}^{+}, \mathbf{2} \cdot \mathrm{Na}^{+}, \mathbf{2} \cdot 2 \mathrm{Na}^{+}, \mathbf{2} \cdot \mathrm{K}^{+}\right.$, 2.2K $\mathrm{K}^{+}$). The BLYP/6-31G(d) calculated IR spectra of the host 1 and its mono-topic alkali-metal-ion complexes are compared.
\end{abstract}

Key Words : DFT BLYP, $m$ PW1PW91, Complex, Alkali metal ion, Thiacalix[4]biscrown-5

\section{Introduction}

Thiacalix[4]arenes represent a very promising group of macrocyclic compounds with many applications in supramolecular chemistry. ${ }^{1}$ The presence of the four sulfur atoms instead of the methylene bridges imposes many novel, interesting features in the thiacalixarenes ${ }^{2-9}$ compared to classical calixarenes. ${ }^{10}$ NMR studies have indicated that thiacalixarenes are conformationally much more flexible than ordinary calixarene in solution. ${ }^{11}$

The complexation ability of thiacalix[4]arenes towards metal ions has actively been investigated. ${ }^{12}$ The most appealing property of these compounds is their enhanced ability to form metal complexes because of the presence of the sulfur atoms and the enlargement of the calix skeleton that provides a larger cavity. ${ }^{13}$ Thiacalix[4] arene-crown is one of the obvious classes of ionophores that are suitable for selective complexation of alkali metal cations. ${ }^{14}$ Several research groups have reported the synthesis of a number of 1,3-altthiacalix[4]bis(crown-5 and -6) ethers. ${ }^{15}$ Recently, thiacalix[4]biscrown-5 (1) and its complexes with alkali-metal cations have been calculated by density functional theory (MPWB1K/6-31G(d)//B3LYP/6-31G(d)) method. ${ }^{16}$

In this study, the structures and energies of thiacalix[4]biscrown-5 (1) and p-tert-butylthiacalix[4]biscrown-5 (2) and their alkali-metal-ion complexes were investigated using the $m$ PW1PW91/6-31G(d,p) (hybrid HF-DF) calculations. The primary objective of this research was to determine the selectivity of the mono- and di-topic complexations of hosts $\mathbf{1}$ and $\mathbf{2}$ with sodium and potassium cations. The secondary objective was to compare the strengths of the cation-oxygen interactions by measuring the $m \mathrm{PW} 1 \mathrm{PW} 91 / 6-31 \mathrm{G}(\mathrm{d}, \mathrm{p})$ optimized distances between the oxygen atoms of the hosts and the alkali metal ions for the alkali-metal-ion complexes.
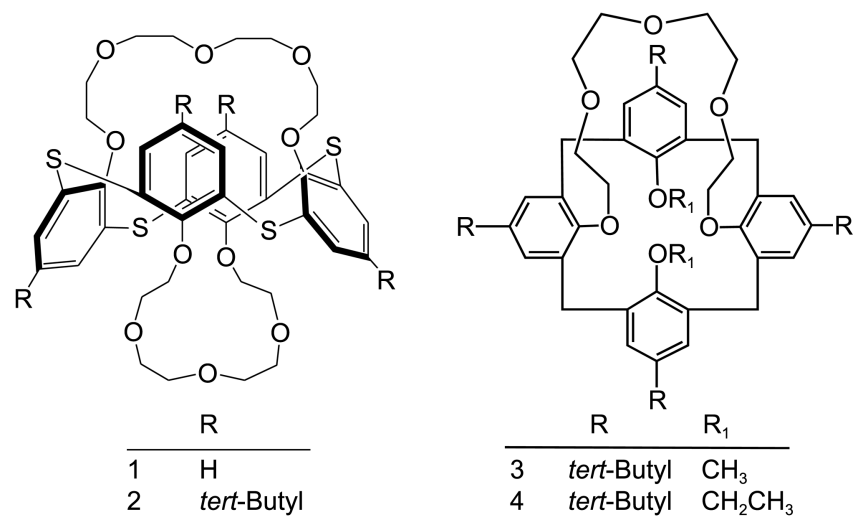

Scheme 1. Chemical drawings of thiacalix[4]biscrown-5 (1), $p$ tert-butylthiacalix[4]biscrown-5 (2) and $p$-tert-butylcalix[4]crown5 (3 and $\mathbf{4})$.

The third objective was to compare the BLYP/6-31G(d) calculated IR spectra of the host $\mathbf{1}$ and its mono-topic alkalimetal-ion complexes.

\section{Computational Methods}

The initial structures of thiacalix[4]biscrown-5 (1 and 2) and their alkali-metal-ion complexes were constructed using the molecular mechanics (MM), molecular dynamics (MD), and AM1 semi-empirical calculations of HyperChem. ${ }^{17}$ The conformational search was executed using the simulated annealing method, as described in a previous publication, in order to determine the optimized structures. ${ }^{18}$ The host and complexes of $\mathbf{1}$ and $\mathbf{2}$ with $\mathrm{Na}^{+}$and $\mathrm{K}^{+}$were fully reoptimized using a DFT BLYP method in order to determine the relative energies and structures of the complexes. The DFT BLYP/6-31(d) calculation was also used to obtain the 
normal mode frequencies and the Gibbs free energies of the optimized structures. Each vibrational spectrum did not exhibit any negative frequencies, confirming that the optimized structures existed in the energy minima. For direct comparison with experimental data, the calculated IR frequencies were scaled by the recommended scale factor $(0.893) .{ }^{19}$ Furthermore, broadened IR spectra are presented assuming a Lorentzian line width of $10 \mathrm{~cm}^{-1}$.

The modified Perdew-Wang 1-parameter ( $m$ PW1) calculation methods, such as $m$ PW1PW91, are new hybrid HartreeFock-density functional (HF-DF) models, which provide remarkable results both for covalent and non-covalent interactions. $^{20}$ In this work, Additional $m$ PW1PW91/6-31G(d) and mPW1PW91/6-31G(d,p) optimizations were performed using Gaussian $03^{21}$ to obtain more accurate total electronic energies and structures for the hosts (1 and 2) and their alkali-metal-ion complexes.

\section{Results and Discussion}

The consecutive BLYP/6-31G(d), mPW1PW91/6-31G(d) and $m \mathrm{PW} 1 \mathrm{PW} 91 / 6-31 \mathrm{G}(\mathrm{d}, \mathrm{p})$ full optimizations without any constraint were carried out for two types (mono- and ditopic) of complexation modes of hosts $\mathbf{1}$ and $\mathbf{2}$ with the sodium and potassium ions.

Tables 1 shows the BLYP/6-31G(d) calculated total electronic and Gibbs free energies and the $m$ PW1PW91/6$31 \mathrm{G}(\mathrm{d})$ and $/ 6-31 \mathrm{G}(\mathrm{d}, \mathrm{p})$ optimized total energies of host (1) and its alkali-metal-ion complexes. Table 2 provides the BLYP/6-31G(d) energies and the $m$ PW1PW91/6-31G(d) and $/ 6-31 G(d, p)$ optimized total energies of host (2) and its alkali-metal-ion complexes. The normal mode frequency analysis was not performed for the bigger host (2) because of the limited computation resources. Therefore, the Gibbs free energies are not listed in Table 2. Tables 1 and 2 also report the total dipole moment obtained from the mPW1PW91/ 6-31G(d,p) optimized structure.

From the $m$ PW1PW91/6-31G(d,p) calculated complexation energies in Tables 1 and 2, the monotopic potassiumcomplexes $\left(\mathbf{1} \cdot \mathrm{K}^{+}:-75.3, \mathbf{2} \cdot \mathrm{K}^{+}:-68.8 \mathrm{kcal} / \mathrm{mol}\right)$ showed about $20 \%$ weaker binding efficiency than the sodium analogue $\left(\mathbf{1} \cdot \mathrm{Na}^{+}\right.$: $\left.-93.8, \mathbf{2} \cdot \mathrm{Na}^{+}:-89.0 \mathrm{kcal} / \mathrm{mol}\right)$. These results were interesting because the complexation energy for the potassium cation binding to an oxygen atom was approximately $25-30 \%$ smaller than a sodium ion. (The MP2/6$311+\mathrm{G}^{*}$ calculations suggested that cation-oxygen binding energy were $-25.4\left(\mathrm{Na}^{+}\right)$and $-19.6\left(\mathrm{~K}^{+}\right) \mathrm{kcal} / \mathrm{mol}$ when a cation was bound to an anisole-oxygen. ${ }^{22}$ The cation-oxygen binding energies were $-26.2\left(\mathrm{Na}^{+}\right)$and $-18.1\left(\mathrm{~K}^{+}\right) \mathrm{kcal} / \mathrm{mol}$ when a cation was bound to the O-H group of phenol from the HF/6-311G(d,p) calculation. $\left.{ }^{23}\right)$

Therefore, we can conclude that the $\mathrm{K}^{+}$-complexes exhibited relatively stronger binding efficiencies than the $\mathrm{Na}^{+}-$ analogues for both the mono- and di-topic complexes of $\mathbf{1}$ and $\mathbf{2}$ comparing the efficiencies of the sodium and potassium complexes with an anisole and phenol. And the mPW1PW91/ 6-31G(d,p) optimized binding energy of potassium-complex $\left(1 \cdot \mathrm{K}^{+}:-75.3 \mathrm{kcal} / \mathrm{mol}\right)$ is bigger than the previously reported value $\left(1 \cdot \mathrm{K}^{+}:-58.4 \mathrm{kcal} / \mathrm{mol}\right)^{16}$ obtained from the single point calculation by MPWB1K/6-31G(d) method using the B3LYP/6-31G(d) optimized structure except for the potassium ion which was computed by LANL2DZ basis set.

The binding efficiencies of the potassium cation toward the ligands ( $\mathbf{1}$ and $\mathbf{2}$ ) were relatively better than sodium cation to an oxygen atom of anisole because the diameter of $\mathrm{K}^{+}(2.66 \AA)$ provided a tighter fit than $\mathrm{Na}^{+}(1.90 \AA)$ with respect to the five ether-oxygen atoms in the crown-5 moiety of the hosts (1 and 2). The necessary number of donor oxy-

Table 1. Calculated total energies of $\mathbf{1}$ and its alkali-metal-ion complexation energies

\begin{tabular}{|c|c|c|c|c|c|}
\hline & \multirow{2}{*}{$\begin{array}{c}E \text { (in a.u) } \\
\text { Host } \mathbf{1}\end{array}$} & \multicolumn{4}{|c|}{$\Delta E_{\text {complex }}{ }^{a}($ in $\mathrm{kcal} / \mathrm{mol})$} \\
\hline & & $\mathbf{1} \cdot \mathrm{Na}^{+}$ & $1 \cdot 2 \mathrm{Na}^{+}$ & $\mathbf{1} \cdot \mathrm{K}^{+}$ & $1 \cdot 2 \mathrm{~K}^{+}$ \\
\hline $\mathrm{BLYP} / 6-31 \mathrm{G}(\mathrm{d})$ & -3894.61736 & -95.8 & -136.2 & -77.1 & -95.3 \\
\hline BLYP/6-31G(d) Gibbs free & $-3893.94098^{b}$ & -87.1 & -117.6 & -68.3 & -75.5 \\
\hline mPW1PW91/6-31G(d) & -3895.06698 & -94.1 & -132.2 & -75.1 & -92.8 \\
\hline mPW1PW91/6-31G(d,p) & -3895.12626 & -93.8 & -132.7 & -75.3 & -92.1 \\
\hline Total dipole moment ${ }^{c}$ & 1.41 & 8.15 & 0.22 & 7.16 & 1.34 \\
\hline
\end{tabular}

${ }^{a} \Delta E_{\text {complex }}$ is defined as the total electronic energy of the complex minus the sum of the total electronic energies of the free ligand and the cation(s). $\Delta E_{\text {complex }}=E_{\text {complex }}-\left(E_{\text {host }}+E_{\text {cation(s) })}\right){ }^{b}$ Sum of the total electronic and thermal Gibbs free energy at $298 \mathrm{~K} .{ }^{c}$ Total dipole moment (Debye) obtained from the mPW1PW91/6-31G(d,p) optimized structure.

Table 2. Calculated total energies of 2 and its alkali-metal-ion complexation energies

\begin{tabular}{|c|c|c|c|c|c|}
\hline & \multirow{2}{*}{$\frac{E \text { (in a.u) }}{\text { Host } 2}$} & \multicolumn{4}{|c|}{$\Delta E_{\text {complex }}{ }^{a}($ in $\mathrm{kcal} / \mathrm{mol})$} \\
\hline & & $2 \cdot \mathrm{Na}^{+}$ & $2 \cdot 2 \mathrm{Na}^{+}$ & $2 \cdot \mathrm{K}^{+}$ & $2 \cdot 2 \mathrm{~K}^{+}$ \\
\hline $\mathrm{BLYP} / 6-31 \mathrm{G}(\mathrm{d})$ & -4523.18205 & -91.4 & -140.5 & -72.9 & -104.8 \\
\hline mPW1PW91/6-31G(d) & -4523.94550 & -79.8 & -121.1 & -60.7 & -78.7 \\
\hline mPW1PW91/6-31G(d,p) & -4524.04724 & -89.0 & -136.6 & -68.8 & -100.3 \\
\hline Total dipole moment & 1.94 & 10.30 & 0.61 & 9.68 & 0.29 \\
\hline
\end{tabular}

${ }^{a}$ See the footnote in Table 1. 


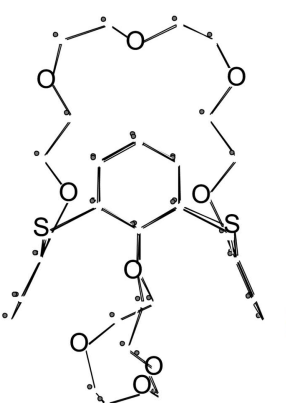

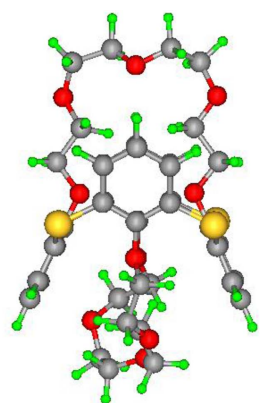

(a) 1 (Host)

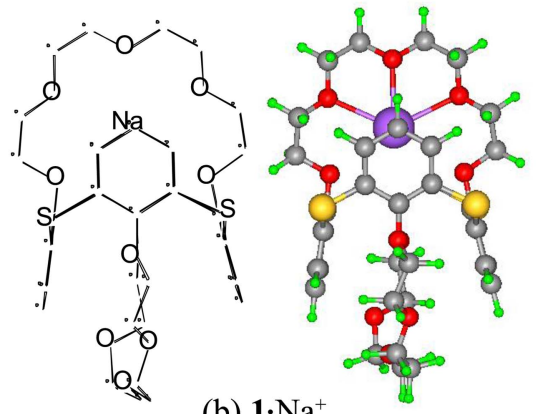

(b) $1 \cdot \mathrm{Na}^{+}$

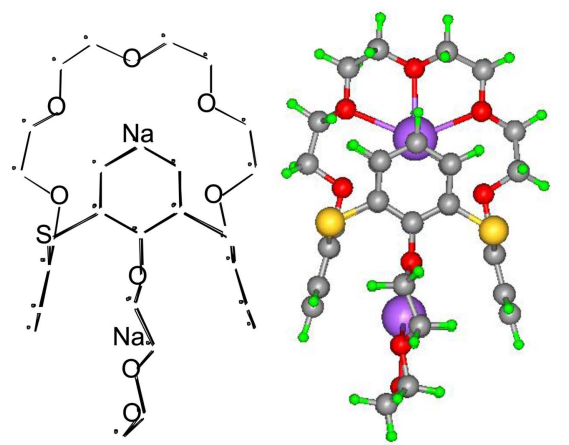

(c) $1 \cdot 2 \mathrm{Na}^{+}$

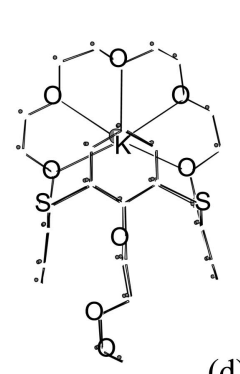

(d) $1 \cdot \mathrm{K}^{+}$

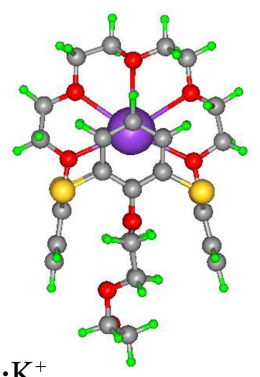

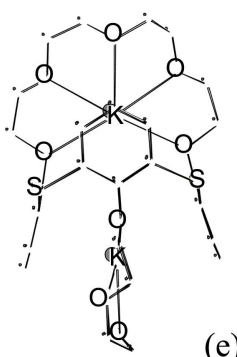

(e) $1 \cdot 2 \mathrm{~K}^{+}$

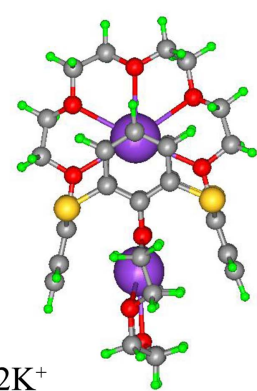

Figure 1. $m \mathrm{PW} 1 \mathrm{PW} 91 / 6-31(\mathrm{~d}, \mathrm{p})$ calculated structures of $\mathbf{1}$ and its alkali-metal-ion complexes that were drawn by $\mathrm{Chem} 3 \mathrm{D}^{24}$ without any hydrogen atoms and PosMol ${ }^{25}$ with all of the atoms. All of the atoms that were within a certain distance (the bond proximate distance) from one another were automatically marked as bonded. ${ }^{24}$

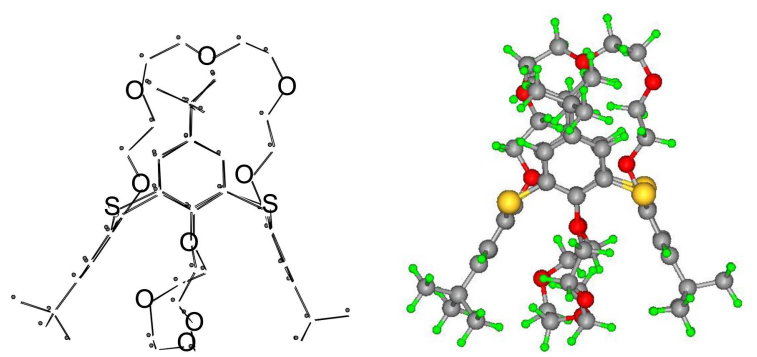

(a) 2 (Host)
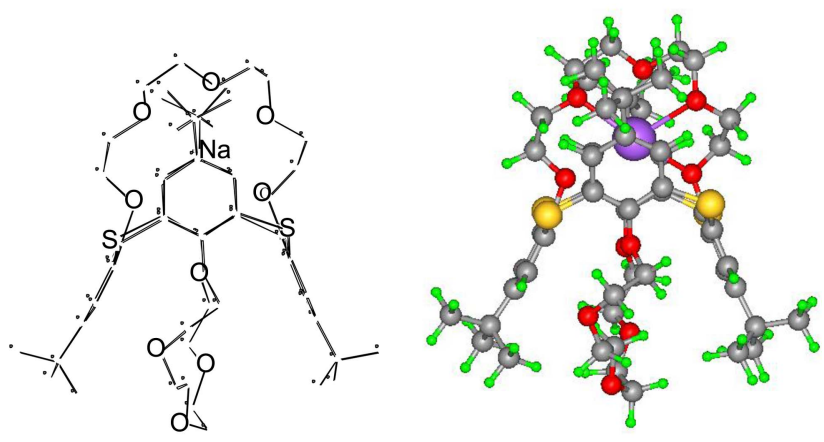

(b) $2 \cdot \mathrm{Na}^{+}$
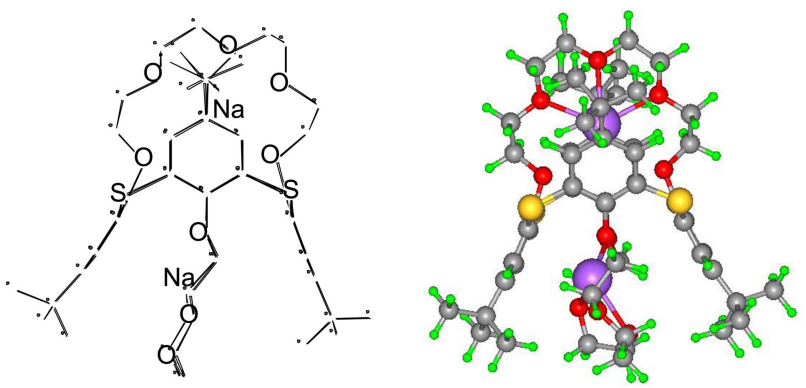

(c) $2 \cdot 2 \mathrm{Na}^{+}$

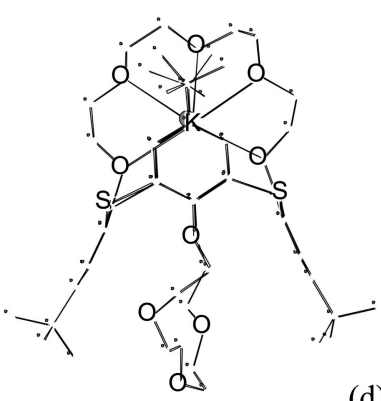

(d) $2 \cdot \mathrm{K}^{+}$
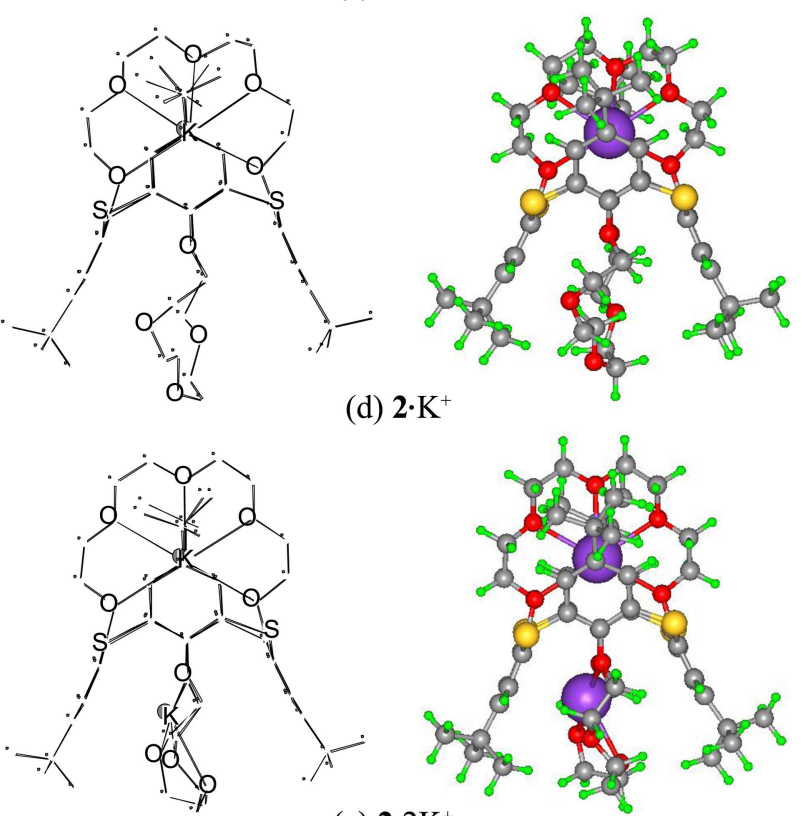

(e) $2 \cdot 2 \mathrm{~K}^{+}$

Figure 2. $m \mathrm{PW} 1 \mathrm{PW} 91 / 6-31(\mathrm{~d}, \mathrm{p})$ calculated structures of 2 and its alkali-metal-ion complexes that were drawn by $\mathrm{Chem}_{3} \mathrm{D}^{24}$ without any hydrogen atoms and $\mathrm{PosMol}^{25}$ with all of the atoms. The atoms that were within a certain distance (the bond proximate distance) from one another were automatically marked as bonded. ${ }^{24}$ 
gen atoms were available, but the crown-5 rings that were attached to calix[4]arene were too large with a somewhat restricted conformational motion, and therefore, appropriate binding sites were not provided for the relatively small $\mathrm{Na}^{+}$ ion.

Interestingly, the $m$ PW1PW91/6-31G(d,p) calculated monotopic binding efficiencies of $p$-tert-butylcalix[4]biscrown-5ether $2(-75.3 \mathrm{kcal} / \mathrm{mole})$ with $\mathrm{K}^{+}$was slightly better than those values calculated from the other $p$-tert-butylcalix[4]crown-5-ethers $(-72.1 \mathrm{kcal} / \mathrm{mole}$ for 3 and $-72.5 \mathrm{kcal} / \mathrm{mole}$ for 4).

Figures 1 and 2 show the $m$ PW1PW91/6-31(d,p) calculated structures of hosts (1 and 2) and their alkali-metal-ion complexes that were drawn by Chem $3 \mathrm{D}^{24}$ without any hydrogen atoms and $\mathrm{PosMol}^{25}$ with all of the atoms. From the Chem3D and PosMol views (Figs. 1(a) and 2(a)) of free hosts 1 and 2, some of the oxygen atoms in the crown-5 moiety did not converge to the center of the crown but randomly pointed outward. In Figures 1(b)-1(e) and 2(b)2(e) for the different complexes of $\mathbf{1}$ and $\mathbf{2}$ with the monoand di-topic alkali-metal ions, all of the oxygen atoms in the crown-5 moiety symmetrically converged to the center of the crown because of the electrostatic attraction from the cation(s).

The distances from the alkali-metal-ion to the oxygen atoms (Table 3 ) and to the centroids of the benzene rings (Table 4) of the ligands (1 and 2) were measured in order to explain the relative binding energies of the different complexes.

When the distances between the akali-metal-ion and the oxygen-atoms were analyzed in Table 3 , the bigger potassium cation(s) were strongly bound to all five crown-5-oxygen atoms of the ligands (see Figs. 1(d) and 1(e)). For the distances from the potassium cation to the oxygen atoms of the ligand in Table 3 , most of the values in the potassiumcomplexes $\left(\mathbf{1} \bullet \mathrm{K}^{+}\right.$and $\left.\mathbf{1} \cdot 2 \mathrm{~K}^{+}\right)$were approximately 2.81
$( \pm 0.12) \AA$. However, for the smaller sodium-complexes $\left(1 \cdot \mathrm{Na}^{+}\right.$and $\left.1 \cdot 2 \mathrm{Na}^{+}\right)$, only three (average $\left.2.52( \pm 0.06) \AA\right)$ out of the five crown-5-oxygen atoms participated in the strong cation-oxygen interactions (see Figs. 1(b) and 1(c)). The HF/ $6-311 \mathrm{G}(\mathrm{d}, \mathrm{p})$ calculation suggested that the optimized binding distance between $\mathrm{Na}^{+}$and the oxygen atom of phenol was $2.20 \AA$, the value for $\mathrm{K}+$ was $2.62 \AA .{ }^{23}$

The binding energies in the complexations of the alkali metal cations with hosts $\mathbf{1}$ and $\mathbf{2}$ were caused by both the multiple cation-oxygen interactions in the crown-5 and the minor contribution of the cation- $\pi$ interactions in the benzene rings of the calix[4]aryl moiety. The B3LYP/6-31G(d) calculations suggested that the cation- $\pi$ binding energies were $-28.5 \mathrm{kcal} / \mathrm{mol}\left(\mathrm{Na}^{+}\right)$and $-18.7 \mathrm{kcal} / \mathrm{mol}\left(\mathrm{K}^{+}\right)$with respect to the benzene ring. ${ }^{26,27}$ The MP2/6-311+G(d) calculations suggested that the cation- $\pi$ interaction energies were $-26.8 \mathrm{kcal} / \mathrm{mol}\left(\mathrm{Na}^{+}\right)$and $-17.8 \mathrm{kcal} / \mathrm{mol}\left(\mathrm{K}^{+}\right)$with respect to the benzene ring, and the perpendicular distances from the center-of-mass of the benzene $\pi$ system to the cation were $2.40 \AA\left(\mathrm{Na}^{+}\right)$and $2.90 \AA\left(\mathrm{K}^{+}\right) .{ }^{28}$ For the cation- $\pi$ interaction in Table 4 , most of the distances from the potassium cation

Table 4. mPW1PW91/6-31G(d,p) calculated distances $(\AA)$ between the arene centroid and the potassium cation(s) in the mono- and ditopic complexes of $\mathbf{1}$ and $\mathbf{2}$

\begin{tabular}{lcccc}
\hline \multirow{2}{*}{ Distance $^{a}$} & \multicolumn{2}{c}{ 1-Complex } & \multicolumn{2}{c}{ 2-Complex } \\
\cline { 2 - 5 } & $\mathbf{1 \cdot K ^ { + }}$ & $\mathbf{1 \cdot 2 K ^ { + }}$ & $\mathbf{2} \cdot K^{+}$ & $\mathbf{2} \cdot 2 \mathrm{~K}^{+}$ \\
\hline Centroid (1) & 3.202 & 3.181 & 2.888 & 2.961 \\
Centroid (2) & 3.225 & 3.292 & $(4.271)$ & $(4.071)$ \\
Centroid (3) & & 3.111 & & 3.421 \\
Centroid (4) & & 3.474 & & 3.576
\end{tabular}

${ }^{a}$ Distance from the potassium cation to the arene centroids of the ligand for strong cation- $\pi$ interaction in the complex. The values in the parentheses exhibited a weak interaction for the long distances from the potassium cation.

Table 3. mPW1PW91/6-31G(d,p) calculated distances $(\AA)$ between the oxygen atoms and the alkali metal ions in the mono- and di-topic complexes of $\mathbf{1}$ and $\mathbf{2}$

\begin{tabular}{|c|c|c|c|c|c|c|c|c|}
\hline \multirow{2}{*}{$\begin{array}{l}\text { Distance } \\
\text { from Cation to }\end{array}$} & \multicolumn{4}{|c|}{ 1-Complex } & \multicolumn{4}{|c|}{ 2-Complex } \\
\hline & $\mathbf{1} \cdot \mathrm{Na}^{+}$ & $1 \cdot 2 \mathrm{Na}^{+}$ & $1 \cdot \mathrm{K}^{+}$ & $\mathbf{1} \cdot 2 \mathrm{~K}^{+}$ & $2 \cdot \mathrm{Na}^{+}$ & $2 \cdot 2 \mathrm{Na}^{+}$ & $2 \cdot \mathrm{K}^{+}$ & $2 \cdot 2 \mathrm{~K}^{+}$ \\
\hline Oxygen (1) & $(2.884)$ & (3.023) & 2.769 & 2.804 & 2.425 & 2.459 & 2.697 & 2.826 \\
\hline Oxygen (2) & 2.625 & 2.479 & 2.746 & 2.784 & 2.585 & 2.453 & 2.755 & 2.759 \\
\hline Oxygen (3) & 2.496 & 2.379 & 2.922 & 2.839 & $(2.728)$ & 2.519 & 2.901 & 2.806 \\
\hline Oxygen (4) & 2.647 & 2.585 & 2.896 & 2.810 & 2.438 & 2.390 & 2.696 & 2.803 \\
\hline Oxygen (5) & $(3.040)$ & $(3.036)$ & 2.794 & 2.802 & $(2.788)$ & $(3.100)$ & 2.821 & 2.862 \\
\hline Average Crown (1) ${ }^{a}$ & 2.589 & 2.481 & 2.825 & 2.808 & 2.483 & 2.455 & 2.774 & 2.811 \\
\hline Oxygen (6) & & (3.089) & & 2.838 & & $(3.026)$ & & 2.760 \\
\hline Oxygen (7) & & 2.543 & & 2.826 & & 2.468 & & 2.692 \\
\hline Oxygen (8) & & 2.381 & & 2.725 & & 2.446 & & 2.789 \\
\hline Oxygen (9) & & 2.510 & & 2.853 & & 2.449 & & 2.714 \\
\hline Oxygen (10) & & $(3.060)$ & & 2.843 & & (3.019) & & 2.742 \\
\hline Average Crown (2) ${ }^{a}$ & & 2.478 & & 2.817 & & 2.454 & & 2.739 \\
\hline
\end{tabular}

${ }^{a}$ Average distance from the cation to the oxygen atoms in the crown-5 moiety for the strong cation-oxygen interaction in the complex. The distances in the parentheses were excluded from the average calculation because the cation-oxygen interactions were weak for those distances in the particular cations. 
Table 5. RMS fits between the host 1 and its cation complexes

\begin{tabular}{ccc}
\hline Compound A & Compound B & RMS fit $(\AA)^{a}$ \\
\hline $\mathbf{1}$ & $\mathbf{1} \cdot \mathrm{Na}^{+}$ & 1.314 \\
$\mathbf{1}$ & $\mathbf{1} \cdot 2 \mathrm{Na}^{+}$ & 1.266 \\
$\mathbf{1}$ & $\mathbf{1} \cdot \mathrm{K}^{+}$ & 1.253 \\
$\mathbf{1}$ & $\mathbf{1} \cdot 2 \mathrm{~K}^{+}$ & 1.235 \\
$\mathbf{1} \cdot \mathrm{Na}^{+}$ & $\mathbf{1} \cdot \mathrm{K}^{+}$ & 0.955 \\
$\mathbf{1} \cdot 2 \mathrm{Na}^{+}$ & $\mathbf{1} \cdot 2 \mathrm{~K}^{+}$ & 0.916 \\
\hline
\end{tabular}

${ }^{a}$ RMS deviation fit (Angstrom) between compound A and compound $\mathrm{B}$ which are the $m$ PW1PW91/6-31G(d,p) optimized structures.

to the arene centroids of the ligand for the 1-complexes were approximately $3.20( \pm 0.20) \AA$ (see Figs. 1(d) and (e)). However, the potassium-arene distances in the 2-complexes were scattered (Figs. 2(d) and (e)). The monotopic complex $\left(1 \bullet \mathrm{K}^{+}\right)(2.888 \AA)$ exhibited a very strong (close) cation- $\pi$ interaction, whereas the other arene $(4.271 \AA)$ for $\mathbf{1} \cdot \mathrm{K}^{+} \mathrm{did}$ not participate in the cation- $\pi$ interaction. The ditopic complex $\left(\mathbf{1} \cdot 2 \mathrm{~K}^{+}\right)(2.961 \AA)$ exhibited strong cation- $\pi$ interactions, whereas two arenes (around $3.50( \pm 0.07) \AA$ ) for $1 \cdot 2 \mathrm{~K}^{+}$exhibited weak interactions, and the fourth one $(4.071$ $\AA$ ) for $\mathbf{1} \cdot 2 \mathrm{~K}^{+}$did not participate in the cation- $\pi$ interaction.

Comparing the calculated C-S bond distances of the two different quantum mechanical methods, the $m \mathrm{PW} 1 \mathrm{PW} 91 / 6-$ $31 \mathrm{G}(\mathrm{d}, \mathrm{p})$ calculated bond distances $(\sim 1.780 \AA)$ between the bridging sulfur and carbon atoms of 1 was $0.034 \AA$ shorter than the average C-S values $(\sim 1.814 \AA)$ from the BLYP calculations of $\mathbf{1}$, but were closer to the experimental values (approximately 1.77-1.78 $\AA$ ). ${ }^{29}$

In order to investigate the rigidity of the host, we have tabulated the RMS fits between the $m$ PW1PW91/6-31G(d,p) optimized structures of the host $\mathbf{1}$ and its alkali-metal-ion complexes in Table 5. These values report that the RMS deviations of $\mathrm{Na}^{+}$and $\mathrm{K}^{+}$complexes are very similar. These calculated data show that the host is fairly rigid and support an additional validity of the relatively stronger binding efficiency of the bigger potassium than the sodium ion.

The BLYP/6-31G(d) calculated IR spectra of the host 1 and its mono-topic alkali-metal-ion complexes are compared in Table 6 and Figure 3. The main features (frequencies and intensities) of host 1 in Figure 5(a) are a little different from its complexes in Figures 5(b) and 5(c). For example, the peaks at $1212 \mathrm{~cm}^{-1}$ of $\mathbf{1} \cdot \mathrm{Na}^{+}$and $1213 \mathrm{~cm}^{-1}$ of $\mathbf{1} \cdot \mathrm{K}^{+}$complex become much stronger due to the concerted vibrations connected complexed cations, while the flexible free host $\mathbf{1}$ displays several weaker lines between 1168 and $1253 \mathrm{~cm}^{-1}$. The detailed descriptions of the individual IR peaks are the following:

The peaks at $683 \mathrm{~cm}^{-1}$ of the host and $685 \mathrm{~cm}^{-1}$ of the complexes come from out-of-plane bending vibrations of aromatic rings and the resulted out-of-plane $\mathrm{C}_{\mathrm{ar}}-\mathrm{H}$ wagging motions. The peaks at 808 and $829 \mathrm{~cm}^{-1}$ of the host 1 arises from the $\mathrm{C}_{\mathrm{cr}}-\mathrm{C}_{\mathrm{cr}}-\mathrm{O}_{\text {ether }}$ bending vibrations of the crown-ether ring. The peaks at $793 \mathrm{~cm}^{-1}$ of the $1 \cdot \mathrm{Na}^{+}$and $787 \mathrm{~cm}^{-1}$ of $1 \cdot \mathrm{K}^{+}$complexes are caused by the puckering motion of the

Table 6. Main features of calculated vibrational modes of $\mathbf{1}$ and its mono-topic alkali-metal-ion complexes

\begin{tabular}{|c|c|c|c|c|c|c|c|}
\hline \multicolumn{3}{|r|}{ Host 1} & \multicolumn{3}{|r|}{$1 \cdot \mathrm{Na}^{+}$} & \multicolumn{2}{|c|}{$1 \cdot \mathrm{K}^{+}$} \\
\hline $\begin{array}{l}\text { Energy }^{a} \\
/ \mathrm{cm}^{-1}\end{array}$ & Int. ${ }^{b}$ & Vibrational mode & $\begin{array}{l}\text { Energy } \\
/ \mathrm{cm}^{-1}\end{array}$ & Int. ${ }^{b}$ & Vibrational mode & $\begin{array}{l}\text { Energy } \\
/ \mathrm{cm}^{-1}\end{array}$ & Int. $^{b}$ \\
\hline 683 & medium & $\begin{array}{l}\text { Out-of-plane bending of } \\
\text { aromatic rings }+ \\
\mathrm{C}_{\mathrm{ar}}-\mathrm{H} \text { wagging }\end{array}$ & 685 & weak & $\begin{array}{l}\text { Out-of-plane bending } \\
\text { of aromatic rings }+ \\
\mathrm{C}_{\mathrm{ar}-\mathrm{H} \text { wagging }}\end{array}$ & 685 & weak \\
\hline $808-829$ & weak & $\mathrm{C}_{\mathrm{cr}}-\mathrm{C}_{\mathrm{cr}}-\mathrm{O}_{\text {ether }}$ bending & 793 & medium & $\begin{array}{l}\text { Puckering of molecular } \\
\text { skeleton }\end{array}$ & 787 & medium \\
\hline 864 & medium & $\begin{array}{l}\mathrm{C}_{\mathrm{cr}}-\mathrm{O}_{\text {ether }} \text { stretching }+ \\
\text { puckering of crown-ether }\end{array}$ & $827-847$ & medium & Bending of crown-ether & $816-829$ & medium \\
\hline 909 & medium & $\begin{array}{l}\text { Symmetric } \\
\mathrm{C}_{\mathrm{cr}}-\mathrm{O}_{\text {ether }} \text { stretching }\end{array}$ & 902 & medium & $\begin{array}{l}\text { Anti-symmetric } \\
\mathrm{C}_{\mathrm{cr}}-\mathrm{O}_{\text {ether }} \text { stretching } \\
\text { (in uncomplexed crown) }\end{array}$ & 909 & medium \\
\hline 958 & strong & $\mathrm{C}_{\mathrm{ar}}-\mathrm{C}_{\mathrm{ar}}$ stretching & 950 & strong & $\begin{array}{l}\text { Anti-symmetric } \\
\mathrm{C}_{\mathrm{cr}}-\mathrm{O}_{\text {ether }} \text { stretching } \\
\text { (in complexed crown) }\end{array}$ & 954 & strong \\
\hline 994 & strong & $\begin{array}{l}\text { Anti-symmetric } \\
\mathrm{C}_{\mathrm{cr}}-\mathrm{O}_{\text {ether }} \text { stretching }\end{array}$ & 987 & strong & $\begin{array}{l}\mathrm{C}_{\mathrm{cr}}-\mathrm{O}_{\text {ether }} \text { stretching } \\
\text { (in uncomplexed crown) }\end{array}$ & 982 & strong \\
\hline 1084 & strong & $\mathrm{C}_{\mathrm{ar}}-\mathrm{O}_{\text {ether }}$ stretching & 1080 & medium & $\begin{array}{l}\mathrm{C}_{\mathrm{ar}}-\mathrm{O}_{\text {ether }} \text { stretching } \\
\text { (in uncomplexed crown) }\end{array}$ & 1076 & medium \\
\hline $1168-1255$ & medium & $\begin{array}{l}\mathrm{C}_{\mathrm{cr}}-\mathrm{H}_{2} \text { wagging } \\
\text { (various motions) }\end{array}$ & 1213 & strong & $\begin{array}{l}\mathrm{C}_{\mathrm{cr}}-\mathrm{H}_{2} \text { wagging } \\
\text { (concerted motion) }\end{array}$ & 1212 & strong \\
\hline $2570-2704$ & strong & Numerous C-H stretching & $2588-2704$ & strong & Numerous C-H stretching & $2593-2706$ & strong \\
\hline
\end{tabular}

${ }^{a}$ The BLYP/6-31G(d) calculated vibrational frequency $\left(\mathrm{cm}^{-1}\right)$ is scaled by multiplication by 0.893 , adjusted it for favorable to comparison with experimental observations. ${ }^{19}{ }^{b}$ Calculated infrared intensity. 


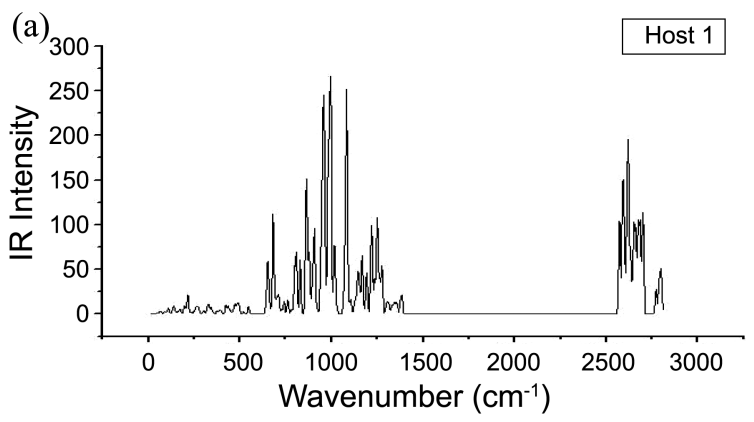

(b)
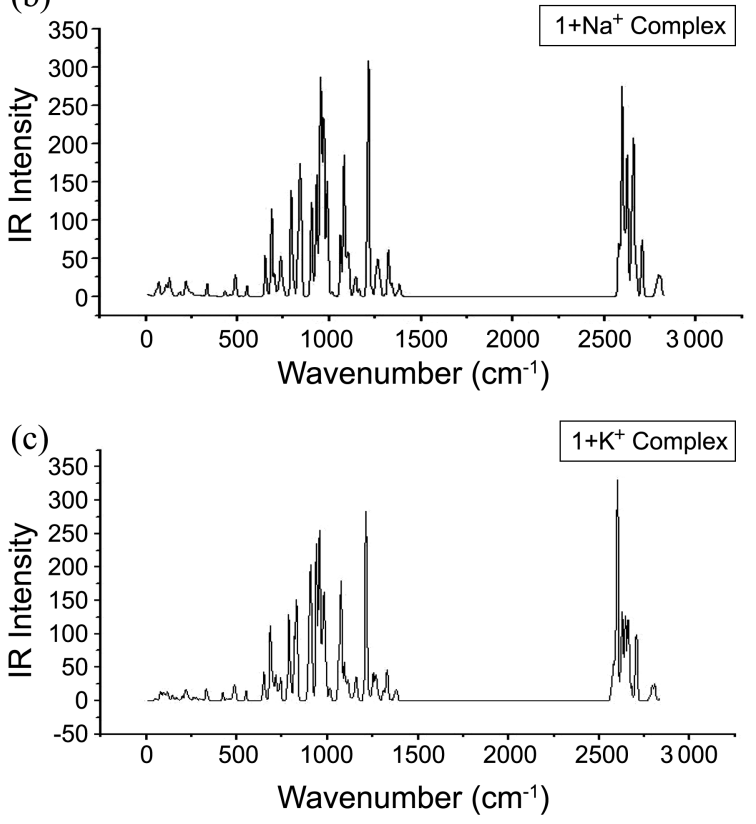

Figure 3. The BLYP/6-31G(d) calculated IR spectra of the free host 1 and its mono-topic alkali-metal-ion complexes 1. (a) Free host $\mathbf{1}$, (b) $\mathbf{1} \cdot \mathrm{Na}^{+}$, and (c) $\mathbf{1} \cdot \mathrm{K}^{+}$. These broadened IR spectra are presented assuming a Lorentzian line width of $10 \mathrm{~cm}^{-1}$.

molecular skeleton. The peaks between 816 and $847 \mathrm{~cm}^{-1}$ of the $1 \cdot \mathrm{Na}^{+}$and $1 \cdot \mathrm{K}^{+}$complexes come from the ring bending vibration of two different crown-ether rings in uncomplexed and complexed with a cation. The peaks at 902 and 909 $\mathrm{cm}^{-1}$ of the complexes arises from anti-symmetric $\mathrm{C}_{\mathrm{cr}}-\mathrm{O}_{\text {ether }}$ (in uncomplexed crown-ether) stretching vibrations. The peaks at 950 and $954 \mathrm{~cm}^{-1}$ of the complexes comes from anti-symmetric $\mathrm{C}_{\mathrm{cr}}-\mathrm{C}_{\mathrm{cr}}$ (in complexed crown-ether) stretching vibrations. The peaks at 982 and $987 \mathrm{~cm}^{-1}$ of the complexes arises from $\mathrm{C}_{\mathrm{cr}}-\mathrm{C}_{\mathrm{cr}}$ (in uncomplexed crown-ether) stretching vibrations.

The peaks at 1076 and $1080 \mathrm{~cm}^{-1}$ of the complexes comes from $\mathrm{C}_{\mathrm{ar}} \mathrm{O}$ bond (in uncomplexed crown-ether) stretching vibrations. The peaks at $1212 \mathrm{~cm}^{-1}$ of $\mathbf{1} \cdot \mathrm{Na}^{+}$and $1213 \mathrm{~cm}^{-1}$ of $\mathbf{1} \cdot \mathrm{K}^{+}$complex arise from the out-of-plane wagging motions of $\mathrm{C}-\mathrm{H}_{2}$ in crown-ether ring. These lines become much stronger than the several weaker peaks between 1190 and $1280 \mathrm{~cm}^{-1}$ the flexible free host 1 . The primary reason of the stronger intensity is that the complexed crown-ether ring causes the concerted vibrations of $\mathrm{C}-\mathrm{H}_{2}$ wagging motions.

The peaks between 2570 and $2706 \mathrm{~cm}^{-1}$ of the host and complexes are composed of the numerous lines of various $\mathrm{C}-\mathrm{H}$ vibrations, such as $\mathrm{C}_{\mathrm{ar}}-\mathrm{H}$ stretching or symmetric and anti-symmetric $\mathrm{C}_{\mathrm{cr}}-\mathrm{H}_{2}$ stretching. Particularly, the peaks at $2598 \mathrm{~cm}^{-1}$ of $\mathbf{1} \cdot \mathrm{Na}^{+}$and $\mathbf{1} \cdot \mathrm{K}^{+}$complex become much stronger due to the concerted $\mathrm{C}-\mathrm{H}$ stretching vibrations, while the flexible free host $\mathbf{1}$ displays weaker lines.

\section{Conclusion}

In this study, $m$ PW1PW91/6-31G(d,p) was optimized for thiacalix[4]biscrown-5 (1), $t$-butylthiacalix[4]biscrown-5 (2), and their alkali-metal-ion complexes. These optimizations suggested that the potassium-complexes of $\mathbf{1}$ and $\mathbf{2}$ exhibited stronger binding efficiencies than sodium-complexes comparing the efficiencies of the sodium and potassium complexes with an anisole and phenol. The bigger potassium cation(s) formed strong bindings with all five crown-5oxygen atoms of the ligands. However, for the smaller sodium-complexes, only three out of the five crown-5oxygen atoms participated in the cation-oxygen interactions. The monotopic binding efficiency of $t$-butylthiacalix[4]biscrown-5 (2) with $\mathrm{K}^{+}$was slightly better than the parent $p$ tert-butylcalix[4]crown-5-ethers (3 and 4). The main IR spectral features of host $\mathbf{1}$ are a little different from its the alkali-metal-ion complexes, such that the peaks of $\mathrm{CH}_{2}$ outof plane wagging vibrations at $1212 \mathrm{~cm}^{-1}$ of $\mathbf{1} \cdot \mathrm{Na}^{+}$and at $1213 \mathrm{~cm}^{-1}$ of $1 \cdot \mathrm{K}^{+}$complex become much stronger than the intensity of the flexible free host $\mathbf{1}$.

Acknowledgments. The theoretical calculations were partly performed by the Research Center for Computational Science, Okazaki, Japan.

\section{References}

1. (a) Kumagai, H.; Hasegawa, M.; Miyanari, S.; Sugawa, Y.; Sato, Y.; Hori, T.; Ueda, S.; Kamiyama, H.; Miyano, S. Tetrahedron Lett. 1997, 38, 3971. (b) Shokova, E. A.; Kovalev, V. V. Russ. J. Org. Chem. 2003, 39, 1. (c) Lhoták, P. Eur. J. Org. Chem. 2004, 1675 .

2. (a) Kim, T. H.; Lee, J. K.; Bok, J. H.; Kim, J. S.; Kim, H. Electrochim. Acta 2004, 49, 3759. (b) Zlatušková, P.; Stibor, I.; Tkadlecová, M.; Lhoták, P. Tetrahedron 2004, 60, 11383. (c) Appelhans, D.; Stastny, V.; Komber, H.; Voigt, D.; Lhoták, P.; Stibor, I. Tetrahedron Lett. 2004, 45, 7145. (d) Iki, N.; Kabuto, C.; Fukushima, T.; Kumagai, H.; Takeya, H.; Miyanari, S.; Miyashi, T.; Miyano, S. Tetrahedron 2000, 56, 1437.

3. Akdas, H.; Bringel, L.; Graf, E.; Hosseini, M. W.; Mislin, G.; Pansanel, J.; De Cian, A.; Fischer, J. Tetrahedron Lett. 1998, 39, 2311.

4. Morohashi, N.; Iki, N.; Sugawara, A.; Miyano, S. Tetrahedron 2001, 57, 5557.

5. Bernardino, R. J.; Costa Cabral, B. J. J. Mol. Struct. (Theochem) 2001, 549, 253.

6. Bilyk, A.; Hall, A. K.; Harrowfield, J. M.; Hosseini, M. W.; Skelton, B. W.; White, A. H. Inorg. Chem. 2001, 40, 672.

7. Iki, N.; Miyano, S. J. Inclusion Phenom. 2001, 41, 99.

8. Matsumiya, H.; Terazono, Y.; Iki, N.; Miyano, S. J. Chem. Soc., Perkin Trans. 2 2002, 1166.

9. (a) Suwattanamala, A.; Magalhães, A. L.; Gomes, J. A. N. F. J. Phys. Chem. A 2005, 109, 10742. (b) Suwattanamala, A.; Magalhães, 
A. L.; Gomes, J. A. N. F. Chem. Phys. Lett. 2004, 385, 368. (c) Kim, K.; Choe, J.-I. J. Korean Chem. Soc. 2009, 53, 521.

10. (a) Mandolini, L., Ungaro, R., Eds.; Calixarenes in Action; World Scientific Publishers Co.: Singapore, 2007. (b) Gutsche, C. D. Calixarenes Revisited; Royal Society of Chemistry: Cambridge, 1998. (c) Calixarenes' 50th Anni Versary; Vicens, J., Asfari, Z., Harrowfield, J. M., Eds.; Kluwer: Dordrecht, 1995.

11. Sone, T.; Ohba, Y.; Moriya, K.; Kumada, H.; Ito, K. Tetrahedron 1997, 53, 10689.

12. (a) Iki, N.; Kumagai, H.; Morohashi, N.; Ejima, K.; Hasegawa, M.; Miyanari, S.; Miyano, S. Tetrahedron Lett. 1998, 39, 7559. (b) Iki, N.; Narumi, F.; Fujimoto, T.; Morohashi, N.; Miyano, S. J. Chem. Soc., Perkin Trans. 2 1998, 2745. (c) Lamartine, R.; Bavoux, C.; Vocanson, F.; Martin, A.; Senlis, G.; Perrin, M. Tetrahedron Lett. 2001, 42, 1021

13. Morohashi, N.; Narumi, F.; Iki, N.; Hattori, T.; Miyano, S. Chem. Rev. 2006, 106, 5291.

14. (a) van Leeuwen, F. W. B.; Beijleveld, H.; Kooijman, H.; Spek, A. L.; Verboom, W.; Reinhoudt, D. N. J. Org. Chem. 2004, 69, 3928. (b) Csokai, V.; Grün, A.; Parlagh, G.; Bitter, I. Tetrahedron Lett. 2002, 43, 7627.

15. (a) Lamare, V.; Dozol, J. F.; Thuéry, P.; Nierlich, M.; Asfari, Z.; Vicens, J. J. Chem. Soc., Perkin Trans. 2 2001, 1920. (b) Grün, A.; Csokai, V.; Parlagh, G.; Bitter, I. Tetrahedron Lett. 2002, 43, 4153. (c) Lee, J. K.; Kim, S. K.; Bartsch, R. A.; Vicens, J.; Miyano, S.; Kim, J. S. J. Org. Chem. 2003, 68, 6720.

16. Hong, J.; Lee, C.; Ham, S. Bull. Korean Chem. Soc. 2010, $31,453$.

17. HyperChem Release 7.5, Hypercube, Inc.: Waterloo, Ontario, Canada, 2002.

18. Choe, J.-I.; Kim, K.; Chang, S.-K. Bull. Korean Chem. Soc. 2000 , 21,465 .

19. Exploring Chemistry with Electronic Structure Methods, 2nd ed.; Foresman, J. B., Frisch, A., Eds.; Gaussian Inc.: Pittsburgh, PA, 1996; p 63: Raw normal vibrational frequency values computed at the Hartree-Fock level contain known systematic errors due to the neglect of electron correlation, resulting in overestimates of about $10 \%-12 \%$.

20. (a) Adamo, C.; Barone, V. J. Chem. Phys. 1998, 108, 664. (b) Zhao, Y.; Tishchenko, O.; Truhlar, D. G. J. Phys. Chem. B 2005,
109, 19046. (c) Lynch, B. J.; Fast, P. L.; Harris, M.; Truhlar, D. G. J. Phys. Chem. A 2000, 104, 4811.

21. Frisch, M. J.; Trucks, G. W.; Schlegel, H. B.; Scuseria, G. E.; Robb, M. A.; Cheeseman, J. R.; Montgomery, J. A., Jr.; Vreven, T.; Kudin, K. N.; Burant, J. C.; Millam, J. M.; Iyengar, S. S.; Tomasi, J.; Barone, V.; Mennucci, B.; Cossi, M.; Scalmani, G.; Rega, N.; Petersson, G. A.; Nakatsuji, H.; Hada, M.; Ehara, M.; Toyota, K.; Fukuda, R.; Hasegawa, J.; Ishida, M.; Nakajima, T.; Honda, Y.; Kitao, O.; Nakai, H.; Klene, M.; Li, X.; Knox, J. E.; Hratchian, H. P.; Cross, J. B.; Bakken, V.; Adamo, C.; Jaramillo, J.; Gomperts, R.; Stratmann, R. E.; Yazyev, O.; Austin, A. J.; Cammi, R.; Pomelli, C.; Ochterski, J. W.; Ayala, P. Y.; Morokuma, K.; Voth, G. A.; Salvador, P.; Dannenberg, J. J.; Zakrzewski, V. G.; Dapprich, S.; Daniels, A. D.; Strain, M. C.; Farkas, O.; Malick, D. K.; Rabuck, A. D.; Raghavachari, K.; Foresman, J. B.; Ortiz, J. V.; Cui, Q.; Baboul, A. G.; Clifford, S.; Cioslowski, J.; Stefanov, B. B.; Liu, G.; Liashenko, A.; Piskorz, P.; Komaromi, I.; Martin, R. L.; Fox, D. J.; Keith, T.; Al-Laham, M. A.; Peng, C. Y.; Nanayakkara, A.; Challacombe, M.; Gill, P. M. W.; Johnson, B.; Chen, W.; Wong, M. W.; Gonzalez, C.; Pople, J. A. Gaussian 03, Revision D.01, Gaussian, Inc., Wallingford CT, 2004.

22. Nicholas, J. B.; Hay, B. P. J. Phys. Chem. A 1999, 103, 9815.

23. Bernardino, R. J.; Cabral, C. Supramol. Chem. 2002, 14, 57.

24. Chem $3 D$, Version 7.0, Cambridge Soft, Cambridge, MA, U.S.A., 2001.

25. Lee, S. J.; Chung, H. Y.; Kim, K. S. Bull. Korean Chem. Soc. 2004, 25,1061

26. Choi, H. S.; Suh, S. B.; Cho, S. J.; Kim, K. S. Proc. Natl. Acad. Sci. 1998, 95, 12094.

27. Marcias, A. T.; Norton, J. E.; Evanseck, J. D. J. Amer. Chem. Soc. 2003, 125, 2351.

28. Kim, D.; Hu, S.; Tarakeshwar, P.; Kim, K. S.; Lisy, J. M. J. Phys. Chem. A 2003, 107, 1228.

29. (a) Kabuto, C.; Higuchi, Y.; Niimi, T.; Hamada, F.; Iki, N.; Morohashi, N.; Miyano, S. J. Inclusion Phenom. Macrocyclic Chem. 2002, 42, 89. (b) Himl, M.; Pojarova, M.; Stibor, I.; Sykora, J.; Lhotak, P. Tetrahedron Lett. 2005, 46, 461. (c) Dvorakova, H.; Lang, J.; Vlach, J.; Sykora, J.; Cajan, M.; Himl, M.; Pojarova, M.; Stibor, I.; Lhotak, P. J. Org. Chem. 2007, 72, 7157. 